Supporting information for:

\title{
Kinked-Helix Actinide Polyrotaxanes from Weakly Bound Pseudorotaxane Linkers with Variable Conformations
}

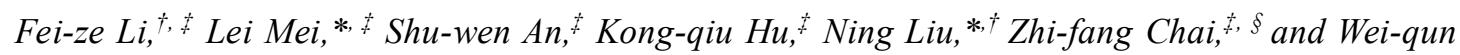
$S h i^{* *+}$

${ }^{\dagger}$ Key Laboratory of Radiation Physics and Technology (Sichuan University), Ministry of Education; Institute of Nuclear Science and Technology, Sichuan University, Chengdu 610064, P. R. China

${ }^{\ddagger}$ Laboratory of Nuclear Energy Chemistry, Institute of High Energy Physics, Chinese Academy of Sciences, Beijing 100049, P. R. China

${ }^{\S}$ Engineering Laboratory of Advanced Energy Materials, Ningbo Institute of Industrial Technology, Chinese Academy of Sciences, Ningbo, Zhejiang, 315201, P. R. China 


\section{Synthesis of C8BPCEt and C8BPCEt@CB[6]}

Scheme S1 ${ }^{a}$. Synthesis of pseudorataxane precursors C8BPCEt@CB[6]. The barrel-like cartoons in the molecular structure represent simplified depiction of cucurbit[6]uril.
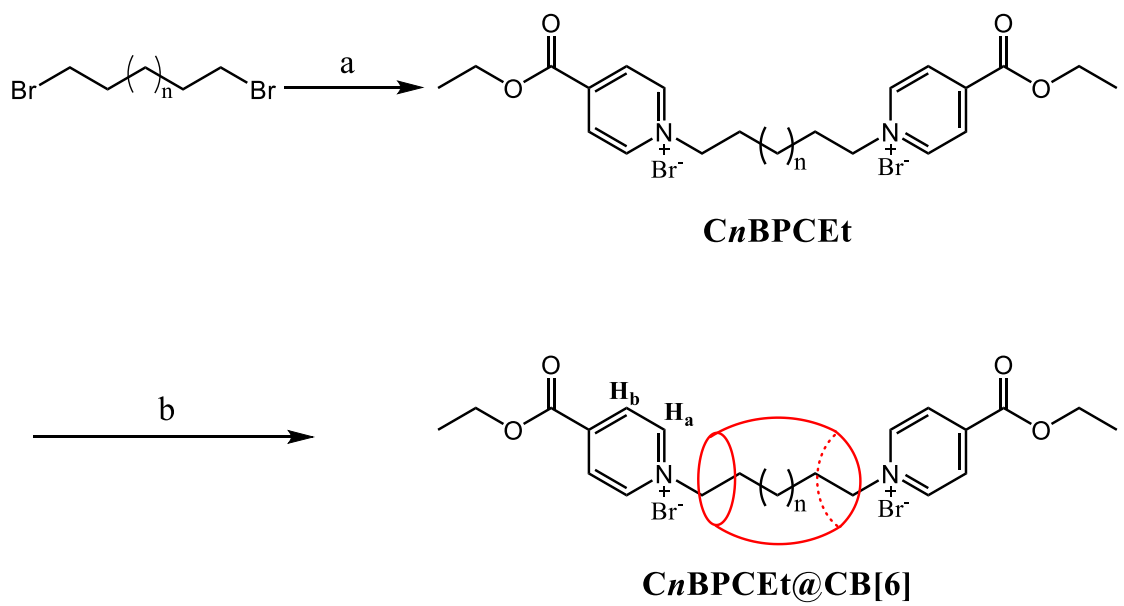

$$
\begin{aligned}
& \text { C6BPCEt@CB[6]; n= } \\
& \text { C7BPCEt@CB[6];n=3 } \\
& \text { C8BPCEt@CB[6];n=4 }
\end{aligned}
$$

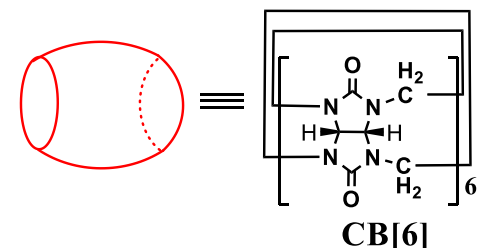

${ }^{a}$ Reagent and conditions: (a) ethyl isonicotinate, $\mathrm{MeCN}$, reflux, $48 \mathrm{~h}$; (b) cucurbit[6]uril, $\mathrm{H}_{2} \mathrm{O}, 100{ }^{\circ} \mathrm{C}, 4 \mathrm{~h}$.

\section{1,1'-(octane-1,8-diyl)bis(4-(ethoxycarbonyl)pyridine-1-ium) bromide (C8BPCEt).}

The synthesis of C8BPCEt was achieved according to a reported procedure. ${ }^{[1,2]}$ Typically, $20 \mathrm{mmol}$ of 1,8-dibromooctane were mixed with $50 \mathrm{mmol}$ of ethyl isonicotinate in $150 \mathrm{~mL}$ of acetonitrile. The mixture was refluxed for $48 \mathrm{~h}$, and allowed to cool to RT naturally. Then, the solution was concentrated to $\sim 20 \mathrm{~mL}$ by evaporation in vacuum and the crude solid was filtered. The obtained solid was sequentially washed with acetone, to remove the excessive ethyl isonicotinate and other intermediates. After being dried under vacuum overnight, the final product C8BPCEt was obtained as light yellow powders, yield: $75.5 \% .{ }^{1} \mathrm{H}$ NMR $\left(500 \mathrm{MHz}, \mathrm{D}_{2} \mathrm{O}, \mathrm{ppm}\right): 9.06$ (d, $\left.J=5.0 \mathrm{~Hz}, 4 \mathrm{H}\right)$, $8.54(\mathrm{~d}, J=5.0 \mathrm{~Hz}, 4 \mathrm{H}), 4.70(\mathrm{t}, J=5.0 \mathrm{~Hz}, 4 \mathrm{H}), 4.53(\mathrm{t}, J=5.0 \mathrm{~Hz}, 4 \mathrm{H}), 2.05(\mathrm{~m}, 4 \mathrm{H}), 1.43(\mathrm{t}, J=$ $7.5 \mathrm{~Hz}, 8 \mathrm{H}), 1.37$ (m, 6H). MS (ESI): mass calculated for $\mathrm{C}_{24} \mathrm{H}_{34} \mathrm{~N}_{2} \mathrm{O}_{4}{ }^{2+}\left(\mathrm{M}^{2+}\right), 414.54 ; \mathrm{m} / \mathrm{z}$ found: $207.07\left(\mathrm{M}^{2+} / 2\right)$ 


\section{Pseudorotaxane precursor C8BPCEt@CB $[6]$.}

The preparation of the pseudorotaxane precursor C8BPCEt@CB[6] was performed through the assembly of C8BPCEt and $\mathrm{CB}[6]$ in aqueous solution. Typically, 2 mmol of C8BPCEt were dissolved in $100 \mathrm{~mL}$ water and $2.5 \mathrm{mmol} \mathrm{CB}[6]$ were added. The solution was refluxed for $\sim 6 \mathrm{~h}$, then naturally cooled to RT. After the filtration of excessive $\mathrm{CB}[6]$, the solution was collected and concentrated to $\sim 10 \mathrm{~mL}$ by evaporation in vacuum. A white solid was obtained after dropping the concentrated solution into absolute alcohol, the crude precipitate was filtered, alternatively washed with absolute alcohol and acetone, and dried under vacuum to afford the final product, yield: $88.76 \%$. ${ }^{1} \mathrm{H}$ NMR (500 MHz, $\left.\mathrm{D}_{2} \mathrm{O}, \mathrm{ppm}\right): 9.31$ and 9.22(d and d, $\left.J=6.5,5.5 \mathrm{~Hz}, 4 \mathrm{H}\right), 8.52$ and 8.37 (d and d, $J=6.0,5.5 \mathrm{~Hz}, 4 \mathrm{H}), 5.72(\mathrm{~d}, J=15.5 \mathrm{~Hz}, 12 \mathrm{H}), 5.49(\mathrm{~s}, 12 \mathrm{H}), 4.67(\mathrm{~m}, 4 \mathrm{H}), 4.50(\mathrm{dd}, J=14.0$, $7.0 \mathrm{~Hz}, 4 \mathrm{H}), 4.25(\mathrm{~d}, J=15.0 \mathrm{~Hz}, 12 \mathrm{H}), 1.78(\mathrm{~m}, 4 \mathrm{H}), 1.41(\mathrm{t}, J=7.0 \mathrm{~Hz}, 6 \mathrm{H}), 0.72(\mathrm{~m}, 4 \mathrm{H}), 0.46$ (m, 4H). MS (ESI): mass calculated for $\mathrm{C}_{63} \mathrm{H}_{70} \mathrm{~N}_{30} \mathrm{O}_{18}{ }^{2+}\left(\mathrm{M}^{2+}\right), 1411.36 ; \mathrm{m} / \mathrm{z}$ found:705.43 $\left(\mathrm{M}^{2+} / 2\right)$.

\section{Reference}

1. Huang, F.; Slebodnick, C.; Mahan, E. J.; Gibson, H. W. [3]Pseudorotaxanes based on the cryptand/monopyridinium salt recognition motif. Tetrahedron 2007, 63 (13), 2875-2881.

2. Sun, X.; Li, B.; Xia, C.; Zhou, X.; Zhang, H. "Liquid-like" type $\left(\mathrm{COO}^{-}\right)_{2}\left(\mathrm{H}_{2} \mathrm{O}\right)_{10}$ anion water clusters in three-dimensional supramolecular structure of cucurbit[6]uril. CrystEngComm 2012, 14 (24), 8525-8529. 
Typical figures

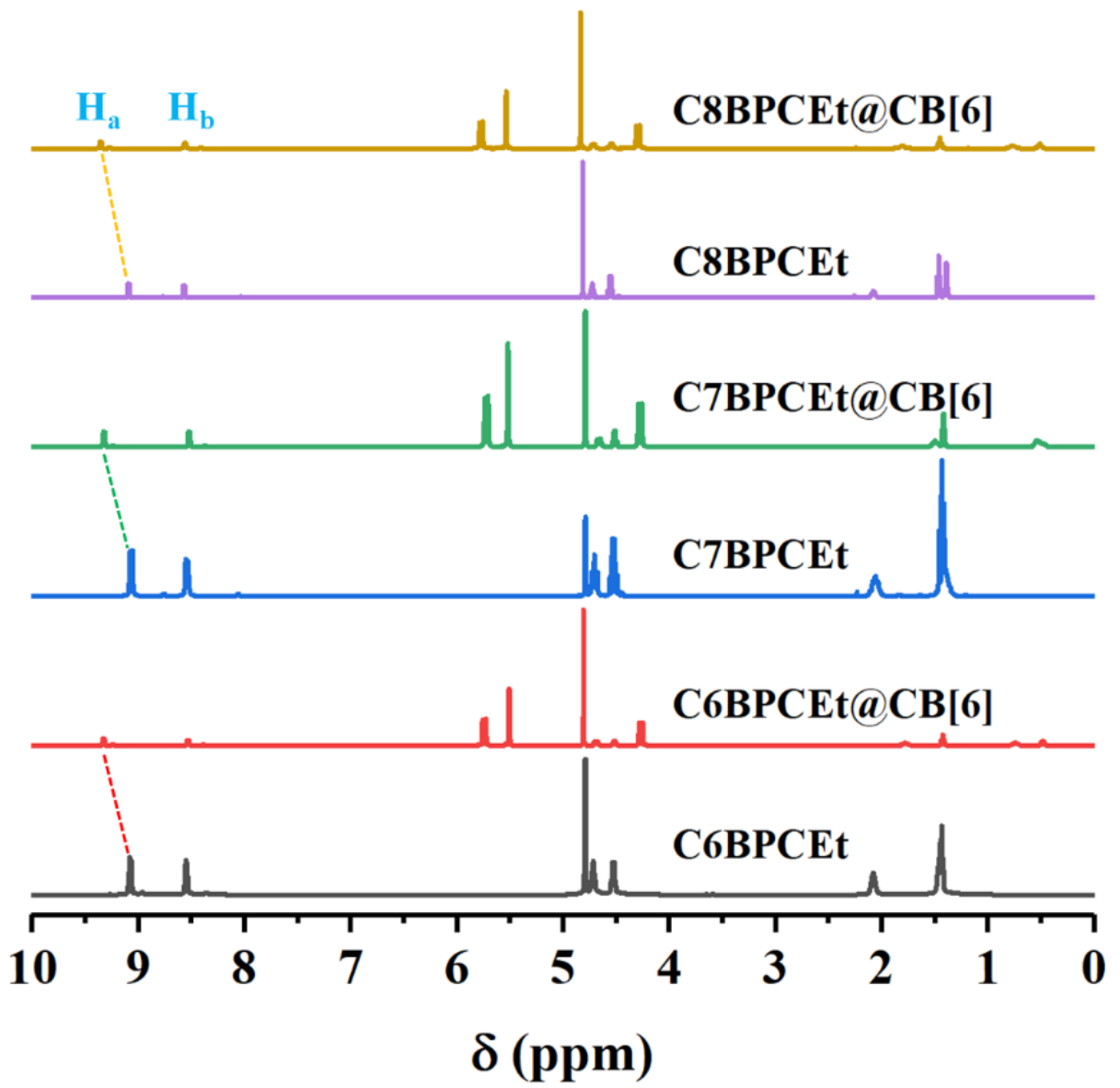

Figure S1. The ${ }^{1} \mathrm{H}$ NMR spectra of C6BPCEt-C8BPCEt and C6BPCEt@CB[6]-C8BPCEt@CB[6] (500 MHz, $\left.298 \mathrm{~K}, \mathrm{D}_{2} \mathrm{O}\right)$. 
(a)
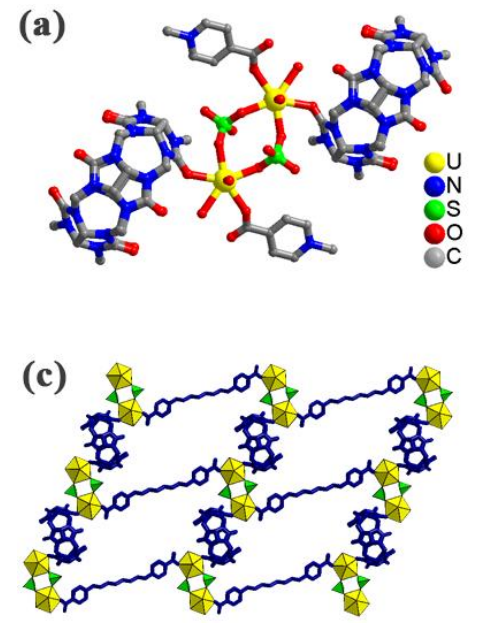

(b)

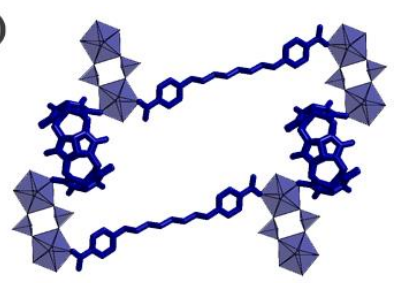

(d)

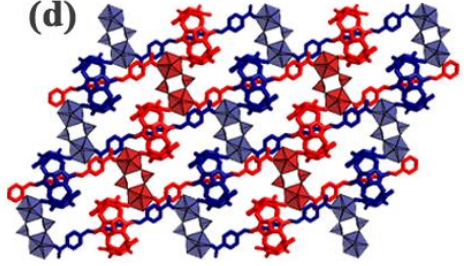

Figure S2. (a) Coordination environment of uranyl cation, (b) the rhomboid building block constructed by CB[6] and C8BPCA, (c) the 2D network constructed by CB[6] and C8BPCA, (d) the 2D polyrotaxane network interwoven by the interlocked feature of pesudorotaxane ligand in URCP1. All hydrogen atoms have been omitted for clarity.

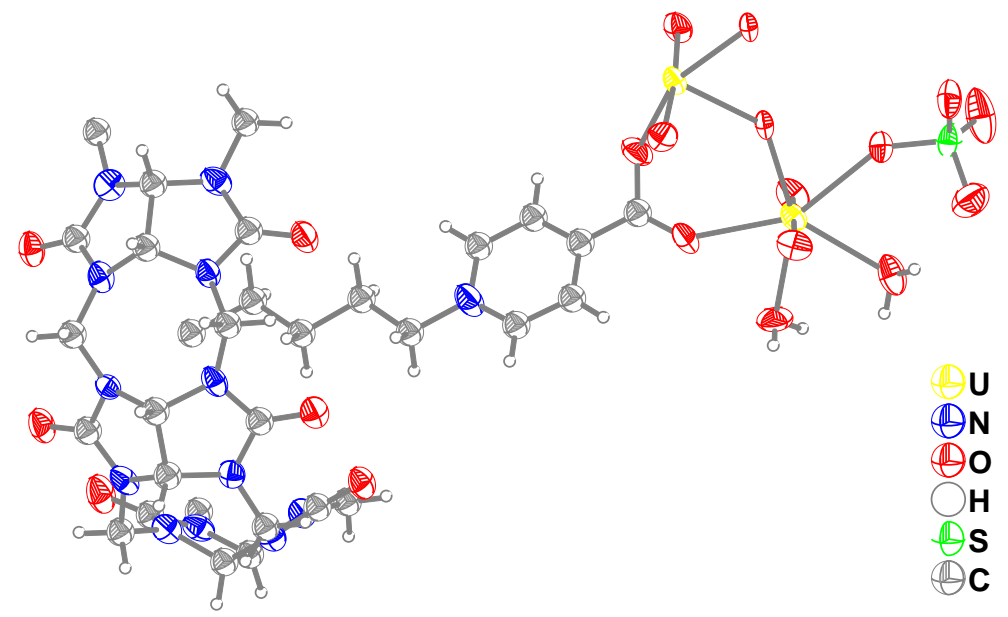

Figure S3. ORTEP drawing of the asymmetric unit of URCP2. Thermal ellipsoids are shown at 50\% probability. All solvent molecules are omitted for clarity. 


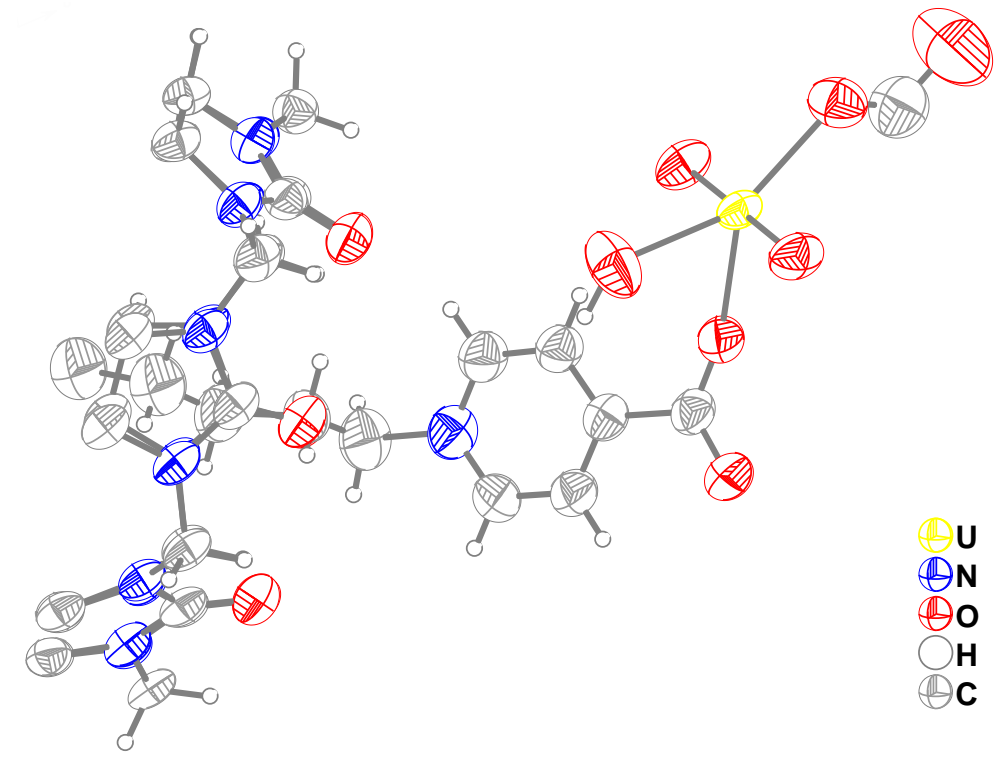

Figure S4. ORTEP drawing of the asymmetric unit of URCP3. Thermal ellipsoids are shown at 50\% probability. All solvent molecules are omitted for clarity.

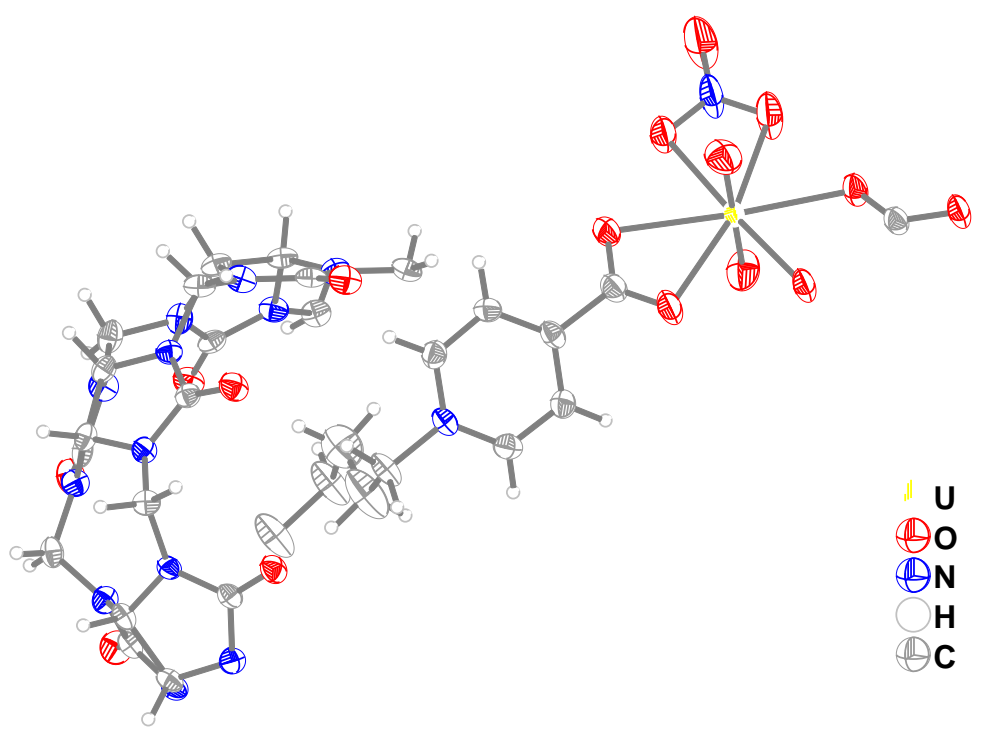

Figure S5. ORTEP drawing of the asymmetric unit of URCP4. Thermal ellipsoids are shown at 50\% probability. All solvent molecules are omitted for clarity. 
(a).

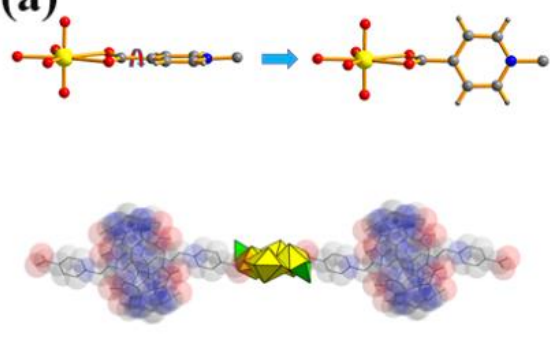

URCP2

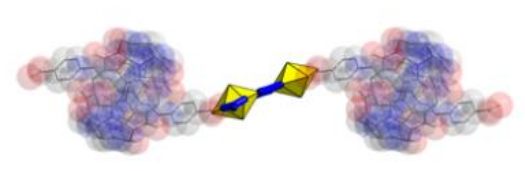

URCP4 (b)
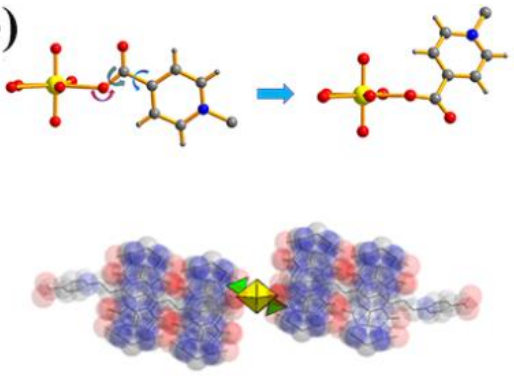

URCP1

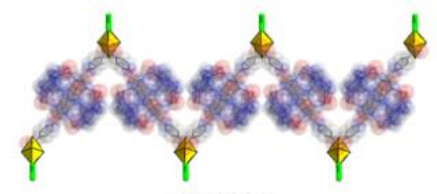

URCP3

Figure S6. (a) bidentate-mode C8BPCA@CB[6] in URCP2 and URCP4, (b) monodentate-mode C8BPCA@CB[6] in URCP1 and URCP3.

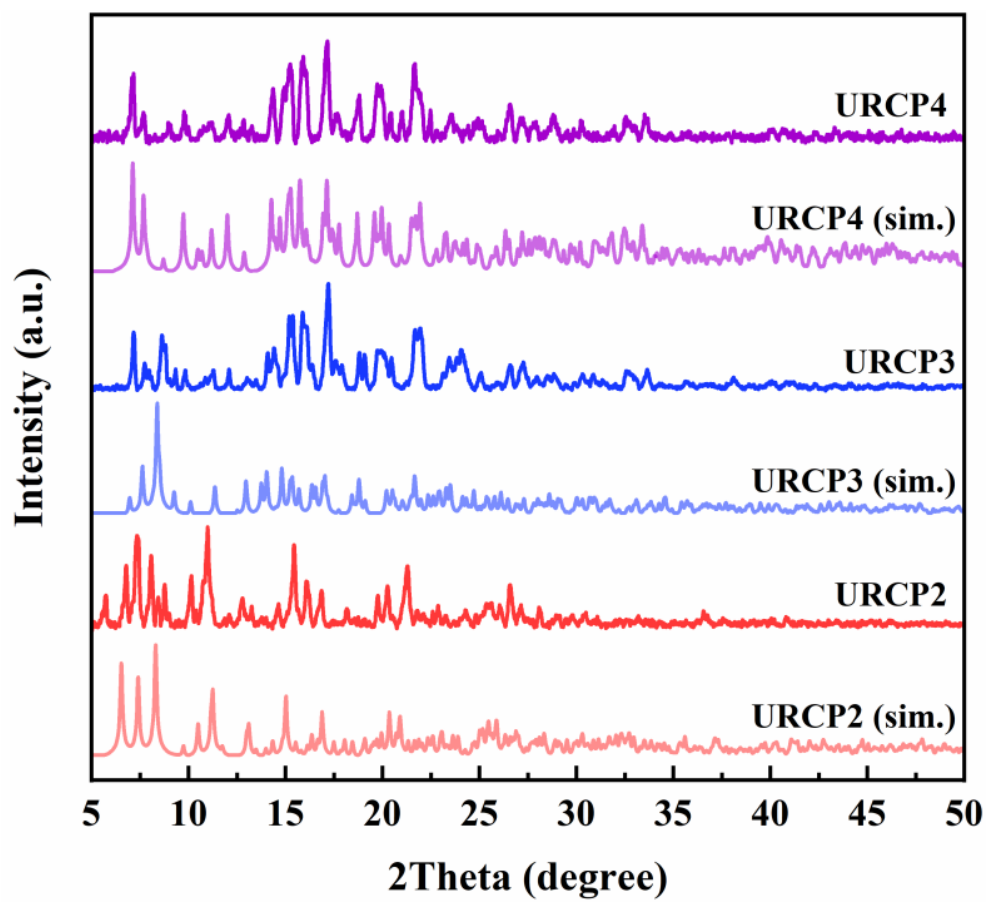

Figure S7. The simulated and as-synthesized PXRD patterns of URCP2-URCP4. 


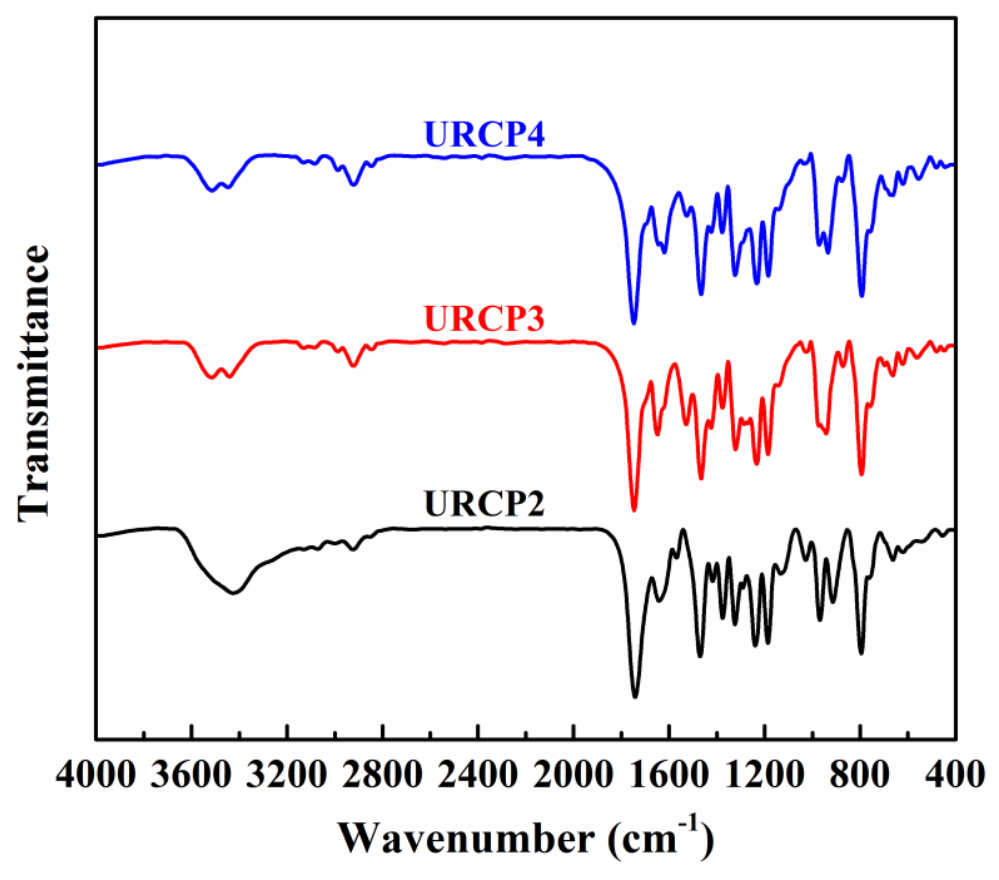

Figure S8. FTIR spectra of URCP2-URCP4.

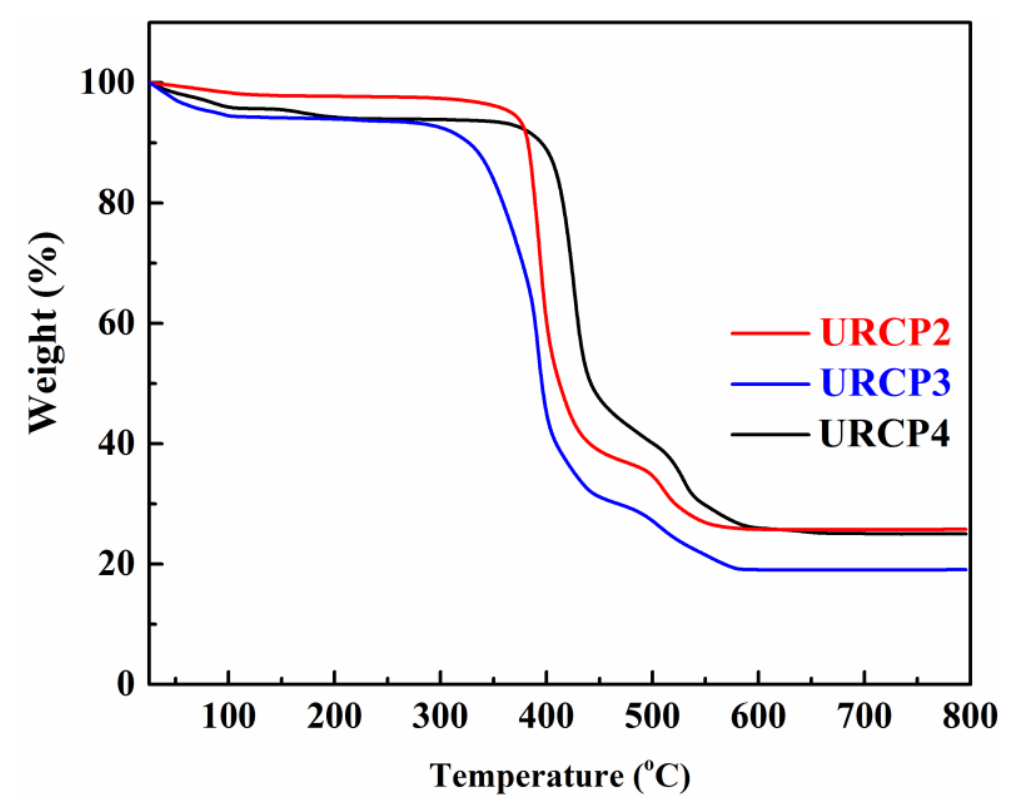

Figure S9. TGA curves of URCP2-URCP4. 


\section{Typical Tables}

Table S1. Selected bond lengths related to the uranyl centers in URCP2-URCP4.

\begin{tabular}{lllll}
\hline Compound & Bond type & Bond length $(\AA)$ & Bond type & Bond length $(\AA)$ \\
\hline \multirow{3}{*}{ URCP2 } & $\mathrm{U} 1-\mathrm{O} 1$ & $1.784(9)$ & $\mathrm{U} 1-\mathrm{O} 2$ & $1.780(9)$ \\
& $\mathrm{U} 1-\mathrm{O} 5$ & $2.247(8)$ & $\mathrm{U} 1-\mathrm{O} 5 \mathrm{~A}$ & $2.330(8)$ \\
& $\mathrm{U} 1-\mathrm{O} 6$ & $2.373(10)$ & $\mathrm{U} 1-\mathrm{O} 7$ & $2.500(10)$ \\
\hline \multirow{2}{*}{ URCP3 } & $\mathrm{U} 1-\mathrm{O} 8$ & $2.499(10)$ & & \\
& $\mathrm{U} 1-\mathrm{O} 1$ & $1.779(8)$ & $\mathrm{U} 1-\mathrm{O} 2$ & $2.337(7)$ \\
\multirow{3}{*}{ URCP4 } & $\mathrm{U} 1-\mathrm{O} 3$ & $2.415(11)$ & $\mathrm{U} 1-\mathrm{O} 4$ & $2.365(8)$ \\
& $\mathrm{U} 1-\mathrm{O} 1$ & $1.755(3)$ & $\mathrm{U} 1-\mathrm{O} 2$ & $1.744(3)$ \\
& $\mathrm{U} 1-\mathrm{O} 3$ & $2.449(3)$ & $\mathrm{U} 1-\mathrm{O} 4$ & $2.449(3)$ \\
& $\mathrm{U} 1-\mathrm{O} 5$ & $2.475(3)$ & $\mathrm{U} 1-\mathrm{O} 6$ & $2.516(3)$ \\
& $\mathrm{U} 1-\mathrm{O} 7$ & $2.507(3)$ & $\mathrm{U} 1-\mathrm{O} 8$ & $2.511(3)$ \\
\hline
\end{tabular}

